\title{
Skene's gland duct cysts: The utility of vaginal/transperineal imaging in diagnosis and mapping for surgery
}

A case series and review of the literature

\author{
P F Kruger, ${ }^{1} \mathrm{MB}$ ChB, FRCS(C) O\&G; R Kung, ${ }^{2} \mathrm{MD}$, FRCS(C) O\&G; F Hamidinia, ${ }^{3}$ CRGS, RDMS; \\ R Rahmani, ${ }^{3} \mathrm{MB} \mathrm{ChB}, \mathrm{FRCP}(\mathrm{C})$, DABR
}

\author{
${ }^{1}$ Department of Obstetrics and Gynaecology, University of Cape Town, South Africa; formerly Department of Obstetrics and Gynecology, \\ University of Toronto, Canada \\ ${ }^{2}$ Department of Obstetrics and Gynecology, University of Toronto, Canada \\ ${ }^{3}$ Department of Radiology, University of Toronto, Canada
}

Corresponding author: P F Kruger (pkruger@urogynaecology.co.za)

We report three patients with Skene's gland cysts diagnosed on transvaginal and transperineal 2D and 3D sonography. We demonstrate that pelvic floor imaging is a useful diagnostic tool and aids in preoperative surgical planning. The real-time nature of this form of imaging and the addition of 3D ultrasonography demonstrate internal architecture and spatial relationships of periurethral pathology, thus aiding presurgical mapping. In this case series patients were followed up and results of surgical procedures and histological findings were recorded. Marsupialisation and resection are accepted surgical options in symptomatic Skene's gland cysts. Usually simple drainage will not suffice for management of a symptomatic Skene's gland cyst, as demonstrated in one of our cases. Asymptomatic cysts can be followed conservatively.

S Afr J Obstet Gynaecol 2016;22(2):62-64. DOI:10.7196/SAJOG.2016.v22i2.1063

Periurethral glands, or Skene's glands, are branched, tubular glands that are adjacent to the distal urethra. Usually Skene's ducts run parallel to the long axis of the urethra for approximately $1 \mathrm{~cm}$ before opening into the distal urethra. Sometimes the ducts open into the area just outside the urethral orifice. Skene's glands are the largest of the paraurethral glands; however, many smaller glands empty into the urethra. Skene's glands are homologous to the prostate in the male. ${ }^{[1]}$

Skene's gland cysts are rare (incidence between 1/2 074 and 1/7 246). They may be either congenital or acquired. Presenting symptoms include a palpable or visible mass at the introitus, pain, dyspareunia, dysuria, a distorted voiding stream and a vaginal discharge. Periurethral cysts may be totally asymptomatic and discovered during routine pelvic examination. ${ }^{[2,3]}$

We discuss the usefulness of imaging the labia, vagina and pelvic floor with $2 \mathrm{D}$ and $3 \mathrm{D}$ vaginal and transperineal pelvic floor sonography.

Ethical approval for this retrospective case series review was granted, and the need for specific patient consent for the study was waived. All patients gave informed verbal consent for all aspects of the sonographic study and signed consent for procedures that were subsequently performed. Examination of the periurethral cysts was done transvaginally and transperineally in all cases.

\section{Case series}

Three consecutive patients with periurethral cysts who presented to a women's ultrasound imaging centre in Toronto between June 2012 and February 2014 were included in this study. Patient information was extracted from the office database of transvaginal sonographic information, maintained by one of the authors. This author also gathered follow-up information regarding surgical management and pathological results on these cases.

\section{Sonographic technique and interpretation}

We demonstrate three patients with the sonographic diagnosis of Skene's gland duct cysts, all proven histologically. Sonography was performed preoperatively with an E8 ultrasound machine (GE Healthcare, UK) employing 2D/3D endovaginal probe (RIC 5-9-D-model, Freq 8-10) to obtain endovaginal and transperineal pelvic floor imaging. All patients underwent colour Doppler sonography to evaluate the presence of vascularity. A senior sonologist who specialises in female ultrasound imaging evaluated all three patients and made the diagnosis preoperatively. The ultrasound masses were evaluated for texture, presence or absence of colour flow, and the anatomical location was mapped on $3 \mathrm{D}$ sonography and $3 \mathrm{D}$ manipulation of the pelvic floor images.

\section{Results}

The results are summarised in Table 1. The patients were aged 29, 39 and 55 years. A total of three Skene's gland duct cysts were seen in 3 patients, and in 2 of the patients additional vaginal cysts were identified. 3D perineal sonography was helpful in establishing the position of the masses in relation to the urethra, aiding the diagnosis. The cysts varied in size between 2.8 and $3.6 \mathrm{~cm}$ (Figs $1-3$ ). 


\section{CASE REPORT}

Table 1. Sonographic findings

\begin{tabular}{|c|c|c|c|c|c|}
\hline Case & Age & Sonographic features and size & Colour Doppler sonography & 3D sonography & Associated findings \\
\hline 1 & 29 & $\begin{array}{l}\text { Lowlevel echoes measuring } \\
3.0 \times 3.0 \times 2.1 \mathrm{~cm} \\
\text { (Fig. 1D) }\end{array}$ & $\begin{array}{l}\text { Present in second mass } \\
\text { indicating septation or } \\
\text { previous infection }\end{array}$ & $\begin{array}{l}\text { Mass lateral to urethra and } \\
\text { separate from it }\end{array}$ & $\begin{array}{l}\text { Second mass in region of right } \\
\text { labia. Measuring } 1.6 \times 1.4 \times \\
2.1 \mathrm{~cm} \text {. More echogenic and } \\
\text { has colour flow. Differential } \\
\text { diagnosis includes canal of } \\
\text { Nuck cyst }\end{array}$ \\
\hline 2 & 55 & $\begin{array}{l}\text { Tubular cystic structure which } \\
\text { encircles the urethra. Right- } \\
\text { sided going anterior and } \\
\text { posterior to urethra towards } \\
\text { the left but dominantly on the } \\
\text { right. Septated. Measures } \\
3.6 \times 1.3 \times 2.2 \mathrm{~cm} \text { (Fig. } 2 \text { ) }\end{array}$ & & & $\begin{array}{l}\text { Vaginal wall Gartner duct cyst } \\
\text { measuring } 2.2 \times 1.3 \mathrm{~cm}\end{array}$ \\
\hline 3 & 39 & $\begin{array}{l}\text { Hypoechoic lesion measuring } \\
2.8 \times 2.7 \times 1.6 \mathrm{~cm} \text { with low- } \\
\text { level echoes (Fig. 3A \& B) }\end{array}$ & & & None \\
\hline
\end{tabular}
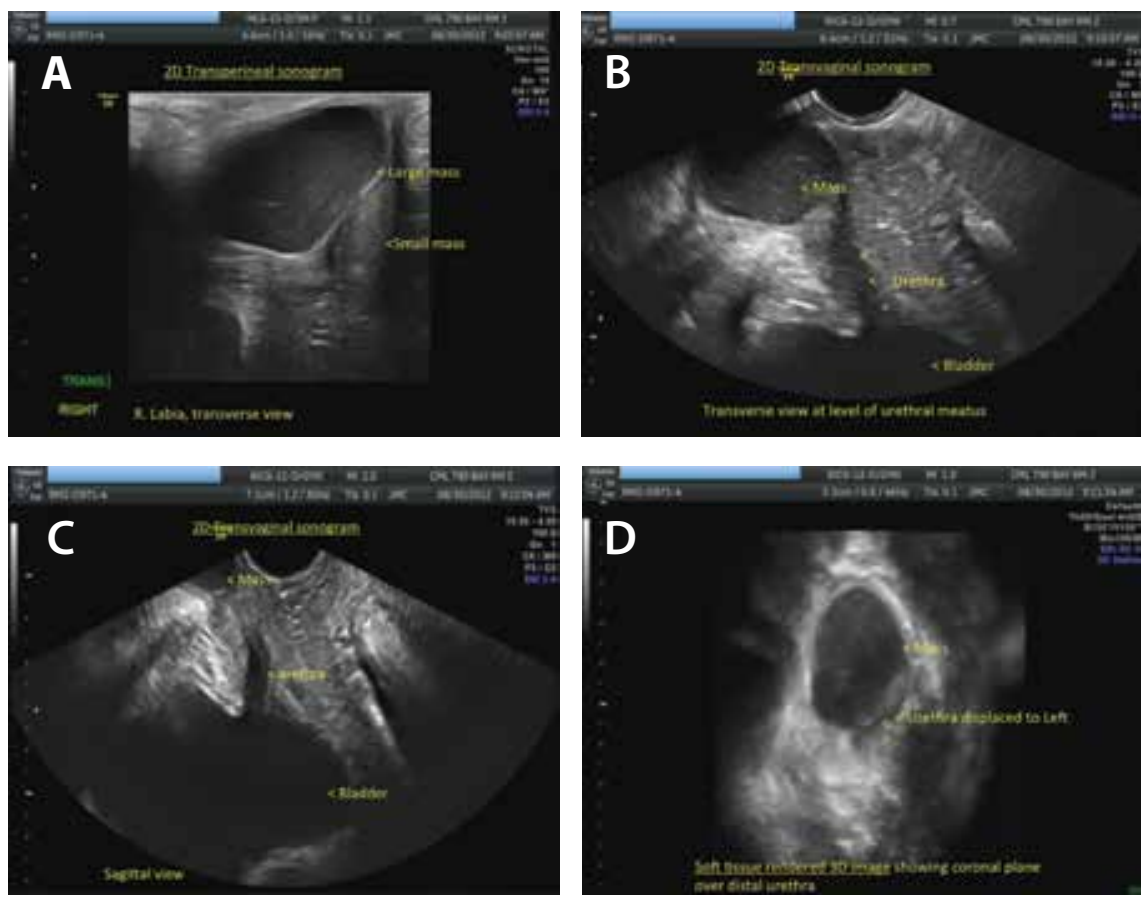

Fig. 1. A. Sonogram of mucinous mass in region of right labia. B. $2 D$ transverse view. $C .2 D$ sagittal view. D. Soft-tissue rendered image demonstrates coronal view of the mass and its relation to the distal urethra. The mass is displacing the urethra to the left.

\section{Management and follow-up}

The referring physicians were informed of the results and management decisions were made after discussion with the patients. Two of the three patients proceeded with surgical excision as the initial approach. A complete resection of the periurethral cyst was possible in case 1. Histopathology confirmed a benign cyst with transitional epithelium. The patient had resolution of her symptoms. The second case presented a difficult surgical excision. Owing to the nature of the cyst and proximity to the urethra, it was not possible to completely excise it. Histopathology confirmed the diagnosis of a benign cyst with transitional epithelium in keeping with a Skene's gland duct cyst. This patient was asymptomatic at her 6 -week postoperative visit. Case 3 opted for drainage at the time of clinical diagnosis. She experienced recurrence within a few weeks and then proceeded with marsupialisation. Histopathology was not obtained. The patient remained asymptomatic at her 6-week follow-up visit.

\section{Discussion}

The spectrum of female urethral and periurethral disorders includes both benign and malignant entities. ${ }^{[5]}$ Benign aetiologies include urethral caruncles, Skene's gland abscess/cysts, mucosal prolapse, ectopic ureterocoele, urethral diverticulum, vaginal wall cysts, Gartner's duct cysts, leiomyomas and hamartomas. ${ }^{[6]}$ Rarely, malignant lesions present as periurethral masses, including adenocarcinoma, squamous cell carcinoma, transitional cell carcinoma, histiocytoma and sarcoma. ${ }^{[5,6]}$

The diagnosis of female periurethral disease is challenging for clinicians because patients present with nonspecific signs and symptoms, including pelvic pain, dyspareunia, dysuria, urinary frequency, urinary urgency, incontinence, urethral bleeding and urinary tract infections. ${ }^{[7]}$

Clinical examination can be unreliable in distinguishing among the many types of urethral or vaginal wall masses. Although conventional imaging studies such as voiding cysto-urethrography and retrograde double-balloon positive-pressure urethrography may be helpful, they are invasive and cannot help map periurethral tissues preoperatively. ${ }^{[8]}$

MRI has become the imaging modality of choice for diagnosis and preoperative planning in female patients with urethral and periurethral disease because of its superb resolution, increased signal-tonoise ratio, and multiplanar capability. The drawback to MRI is high cost and limited access.

With the advent of improved ultrasound high-frequency probes and 3D pelvic floor imaging, transvaginal and transperineal ultra- 


\section{CASE REPORT}

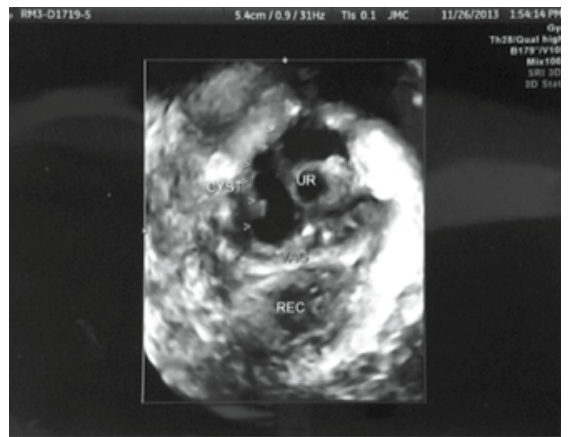

Fig. 2. Transperineal $3 D$ pelvic floor image demonstrating the exact anatomy relationship of Skene's gland duct cyst wrapping the urethra.

sonography is an emerging modality that is being used to evaluate female urethral and periurethral disease in a more cost-effective manner. ${ }^{[5]}$ This form of imaging also has the advantage of being a real-time investigation. With the addition of 3D scanning, the internal architecture and spatial relationships of periurethral pathology can be clearly displayed. The ability to visualise internal characteristics of vaginal cysts and masses is important because it can help surgeons with management decisions. Evaluating the extent of a vaginal mass or cyst and its anatomical landmarks gives important information for precise diagnosis and surgical finding expectations. ${ }^{[1,9]}$

We agree with recent publications that transvaginal ultrasonographic scanning with the addition of 3D scanning can make a significant contribution to the diagnosis

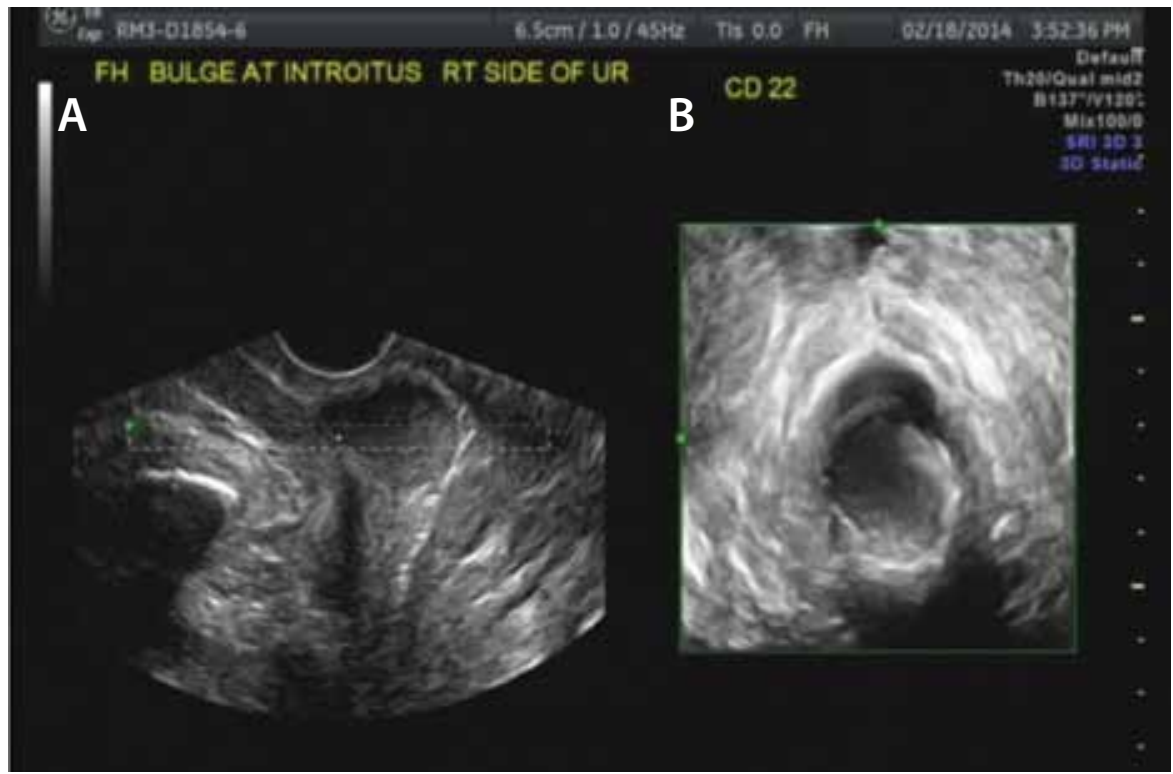

Fig. 3. A. $2 D$ transperineal sonogram image of mucinous mass adjacent to the urethra. $B .3 D$ ultrasound demonstrates the accurate relationship of mucinous mass to other structures in the pelvic floor.

and management of periurethral disease by supplying preoperative information that can aid surgical planning, obviating the need for more costly MRI imaging. ${ }^{[9]}$ This was well illustrated in this case series.

\section{References}

1. Katz VL. Comprehensive gynecology. 5th ed. Philadelphia: Mosby Elsevier, 2007

2. Battaglia C, Venturoli S. 3-D ultrasonographic appearance of two intermittent paraurethral cysts: A case report. J Sex Med 2010;7(8):2903-2906. http://dx.doi.org/10.1111/j.1743 $6109.2009 .01602 \times$

3. Sharifi-Aghdas F, Daneshpajooh A, Mirzaei M. Parauerthral cyst in adult women: Experience with 85 cases. Urol J 2014 1(5):1896-1899.
4. Lucioni A, Rapp DE, Gong EM, Fedunok P, Bales GT Diagnosis and management of periurethral cysts. Urol Int 2007;78(2):121-1215. http://dx.doi.org/10.1159/000098068

5. Chaudhari VV, Patel MK, Douek M, Raman SS. MR imaging and US of female urethral and periurethral disease. Radiographics 2010;30(7):1857-1874. http://dx.doi org/10.1148/rg.307105054

6. Dmochowski RR, Ganabathi K, Zimmern PE, Leach GE Benign female periurethral masses. J Urol 1994;152 (6 Pt 1):1943-1951.

7. Handel LN, Leach GE. Current evaluation and management of female urethral diverticula. Curr Urol Rep 2008;9(5):383-388.

8. Rufford J, Cardozo L. Urethral diverticula: A diagnostic dilemma. BJU Int 2004;94(7):1044-1047. http://dx.doi. org/10.1111/j.1464-410x.2004.05125.x

9. Shobeiri SA, Rostaminia G, White D, Quiroz LH, Nihira MA. Evaluation of vaginal cysts and masses by 3 -dimensional endovaginal and endoanal sonography. $J$ Ultrasound Med 2013;32(8):1499-1507. http://dx.doi.org/10.7863/ ultra.32.8.1499 